\title{
Mentoring future engineers in higher education: a descriptive study using a developed conceptual framework
}

\author{
Darlington Agholor ${ }^{a}$, Álvaro Lleó de Nalda ${ }^{\mathrm{b} *}$, Nicolás Serrano Bárcena ${ }^{\mathrm{b}}$ \\ aPan Atlantic University, Lagos, Nigeria \\ ${ }^{\mathrm{b}}$ Tecnun-School of Engineering, University of Navarra, San Sebastian, Spain \\ *alleo@tecnun.es
}

\begin{abstract}
Mentoring research is recent and multidisciplinary and is found in mostly English speaking cultural contexts. The purpose of this study is to describe a fifty-year old mentoring practice involving faculty-mentors and engineering student-mentees, at the school of engineering of a Spanish university, a non-English speaking context. Mentoring is part of the process of developing the career of the engineering students. For this description, we first developed a more complete conceptual framework of mentoring from literature, identifying the key elements or components. The description of each element in the mentoring practice at the study setting was obtained from archival documents, records, observations and interviews of faculty-mentors and student-mentees. The usefulness of the framework is thereby tested and areas for improvement of the mentoring practice are identified. In addition, this study extends mentoring research into the Spanish speaking European culture and highlights a mentoring experience that could be replicated in other universities. We provide a definition of mentoring that is based on the mentoring experience and practice at the institution given the lack of a generally accepted definition of mentoring.
\end{abstract}

Keywords

Faculty-mentor. Engineering student-mentee. University. Spain.

How to cite this article: Agholor, D., Lleo, A., \& Serrano, N. (2017). Mentoring future engineers in higher education: a descriptive study using a developed conceptual framework. Production, 27(spe), e20162207. http://dx.doi.org/10.1590/01036513.220716

\section{Introduction}

The origin of mentoring as an interpersonal developmental relationship practiced from ancient times is often traced to Homer's Odyssey, the Greek mythology in which Odysseus entrusts his son Telemachus to Mentor, his friend, to help in the upbringing of Telemachus, while he went off to war with the city of Troy. However, research about mentoring is recent given the less than forty years since the pioneering empirical study by Kram (1983). Kram's study opened-up mentoring research especially in workplace/organisational settings (Allen et al., 2008). Mentoring research and practice can now be found in an academic or a higher education context and community or social work contexts (Eby et al., 2007; Gerstein, 1985; Eby \& Allen, 2008).

Specifically, mentoring programmes are being developed in universities for their perceived usefulness in improving students' academic performance and retention (Campbell \& Campbell, 1997). It is seen as a retention and enrichment strategy for undergraduate education (Jacobi, 1991). Faculty mentorship is also viewed as a highly valued type of student-faculty interaction that could lead to many benefits for the students, especially in their first year such as in academic achievement, lifelong learning skills, college persistence, intellectual and social development and adjustment (Fuentes et al., 2014). 
Given such mentoring benefits have been identified, it is reasonable that higher education institutions, including universities and specifically engineering schools, invest resources to introduce mentoring programmes where they do not exist or increase the effectiveness of existing ones. However, in spite of the benefits, one key challenge of the mentoring field is the lack of a unified and generally accepted conceptualisation of mentoring (Jacobi, 1991; Crisp \& Cruz, 2009; Gershenfeld, 2014; Ehrich et al., 2004).

Identifying the key elements or components that comprise a mentoring programme will be useful in this endeavour. Therefore, key research questions of this study are: What are the key components or elements of mentoring? How useful are these components or elements for describing a specific mentoring practice involving engineering students in a non-English speaking higher education context?

Therefore, in this study, first we develop an integrated conceptual framework which incorporates all the key features of mentoring identified in the earlier frameworks in the literature. Subsequently, we apply the developed framework to the study of the more than fifty years of mentoring engineering students at a Spanish University, a non-English speaking context (hereinafter referred to as the engineering university). As most of the mentoring research to date has been carried out in the US and other English speaking countries (Allen et al., 2008; Ehrich et al., 2004; Kezar \& Kinzie, 2006), this descriptive study of a mentoring experience is one of the first in a Spanish cultural context. Subsequently, the usefulness of the framework with the case studied will be verified and areas for improving the effectiveness of the mentoring programme at the engineering university will be identified.

\section{Research methodology}

In order to develop the conceptual framework, we carried out a literature search in the university library database (which has access to PsychINFO, ERIC, EBSCO Host, Academic OneFile, ScienceDirect, Sage, Springerlink, Emerald, ISI web of science), so as to identify existing and available studies focused on mentoring conceptual frameworks or models. The key words searched included "mentoring", "conceptual frameworks" and "model" in different combinations. The relevant literatures identified were then reviewed. The review included ten journal articles that centred on the description of conceptual frameworks published up to 2014. Findings from this review were used to develop the updated mentoring conceptual framework. The ten elements of the conceptual framework formed the basis for the collection of data for the qualitative descriptive study of mentoring experience at the engineering university. We have used qualitative descriptive study to provide a well-grounded, rich description and explanation of mentoring in identifiable local contexts (Miles \& Huberman, 1994). We carried out the qualitative study using in-depth semi-structured face to face interviews of fourteen faculty-mentors (male/female), eight engineering student-mentees (male/female) who were available, and the head of the students affairs unit. The mentors and mentees were asked about their experience of mentoring while the head of students' affairs was asked about how the mentoring programme was designed and is being implemented at the engineering university. Interview durations varied between 30 minutes and 1 hour per interviewee. The researchers prepared the interview questions. The interviews were tape recorded and later transcribed, translated and analyzed manually. Some of the questions in the interview protocol included: What is mentoring? What is your experience of mentoring at the engineering university? Why do you participate in the mentoring programme? What would you say makes students participate more or less in the mentoring programme? What does success in mentoring consist of? In addition, we carried out content analysis of some archival documents about mentoring from the mentoring programme coordination unit of the engineering university. The documents were critically analyzed in terms of their content, authors, purpose, completeness, and signs of bias (Bell, 2005). Furthermore, observation of the students' affairs team meetings for several weeks provided some data as to the functioning of the mentoring programme at the Engineering University.

\section{Development of an updated integrated conceptual framework of mentoring}

Miles \& Huberman $(1994$, p. 18) had defined a conceptual framework as a written or visual presentation that "[...] explains either graphically, or in narrative form, the main things to be studied - the key factors, concepts or variables - and the presumed relationships among them". Different attempts have been made to develop conceptual frameworks from the early years of mentoring research (Hunt \& Michael, 1983; Anderson \& Shannon, 1988; Gaskill, 1993; Wanberg et al., 2003; Baugh \& Fagenson-Eland, 2007; Hegstad, 1999; Young \& Perrewé, 2000; Dawson, 2014). The majority of the frameworks were developed to guide study or research of mentoring in workplace/organisational settings. These frameworks enable us to categorise the relevant aspects or themes from the mentoring literature and to identify the key features and characteristics of mentoring relationships. 
From analysing these frameworks, we develop an updated integrated mentoring framework which incorporates all the elements identified in the earlier frameworks.

\subsection{Analysis of the frameworks}

While it could be said that Hunt \& Michael's (1983) framework is made up of some of the elements or components of mentoring including context, mentor and mentee characteristics, relationship stages, and mentee, mentor and organisational outcomes, Anderson \& Shannon's (1988) model referring to a teacher education context, focuses more on foundational aspects which include a definition of mentoring, the essential functions of the mentor, mentoring activities, and mentors' disposition. There is no evidence from their study to suggest that the model was evaluated to ascertain that it covered all the relevant aspects of a mentoring relationship. Gaskill's (1993) framework which focused on retailing businesses had mentor and mentee selection, training, mentor-mentee linkages, mentoring functions, mentee-mentor-organisational benefits, and programme evaluation as elements. Hegstad's (1999) framework identified mentee, mentor and organisational antecedents and outcomes both positive and negative. Young \& Perrewé's (2000) framework is one of the most comprehensive, identifying such themes or components of mentoring as mentor and mentee characteristics, environmental, career and relationship antecedent factors, relationship type \& phase, participants' willingness to engage, mentor and mentee role behaviours and the outcomes for mentor, mentee and the organisation.

Focusing on the mentor, Johnson (2003), conceptualised the mentor's competence to mentor as a function of mentor character virtues, abilities, aptitudes and competencies (knowledge and skill). Other elements of the framework are mentee-mentor-organisational or institutional benefits, and a definition for mentoring. Wanberg et al. (2003) framework included similar elements such as type of mentoring, mentoring outcomes for mentee, mentor and the organisation, mentoring functions, mentoring relationship characteristics, mentor, mentee and dyad characteristics, and organisational context. Baugh \& Fagenson-Eland's (2007) framework included type of mentoring, mentoring received/functions, programme design and structure, mentor and mentee characteristics, matching process, mentoring relationship characteristics, organisational support, training and outcomes for mentee, and mentor and the organisation. The latest framework by Dawson (2014) is made up of 16 elements for defining the concept of mentoring and these include objectives, roles, cardinality, tie strength, relative seniority, time, selection, matching, activities, resources and tools, role of technology, training, rewards, policy, monitoring and termination.

Analysing the identified mentoring conceptual frameworks and other relevant mentoring literature, for similarities and differences, the above elements or components can be integrated into ten elements or components. These elements make up the integrated mentoring conceptual framework. These include: mentoring definition, type of mentoring, mentoring context, programme structure, mentor characteristics, mentee characteristics, matching process, mentoring relationship characteristics (which includes mentoring functions, mentoring phases and mentoring activities), mentoring outcomes, programme support, as shown in Table 1 below.

Having identified these ten elements or components of the mentoring concept, we now provide a brief overview of each of them supported by the wider mentoring literature.

Table 1. Development of the updated integrated mentoring conceptual framework.

\begin{tabular}{|c|c|c|c|c|c|c|c|c|c|c|}
\hline & 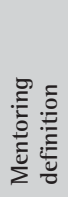 & 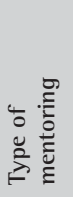 & & 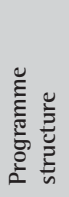 & 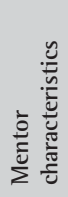 & 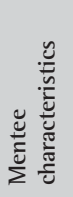 & 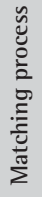 & 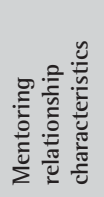 & 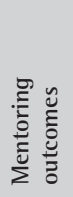 & 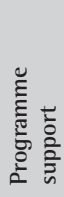 \\
\hline Hunt \& Michael (1983) & & & $\mathrm{x}$ & & $\mathrm{x}$ & $\mathrm{x}$ & & $\mathrm{x}$ & $\mathrm{x}$ & \\
\hline Anderson \& Shannon (1988) & $\mathrm{x}$ & & $x$ & & $x$ & & & $\mathrm{x}$ & & \\
\hline Gaskill (1993) & & & $x$ & & $x$ & $x$ & $\mathrm{x}$ & $\mathrm{x}$ & $x$ & $\mathrm{x}$ \\
\hline Hegstad (1999) & & & $x$ & & $\mathrm{x}$ & $\mathrm{x}$ & & $\mathrm{x}$ & $\mathrm{x}$ & \\
\hline Young \& Perrewé (2000) & & $x$ & $x$ & & $x$ & $x$ & & $x$ & $x$ & \\
\hline Johnson (2003) & $\mathrm{x}$ & & $\mathrm{x}$ & & $\mathrm{x}$ & & & & $x$ & \\
\hline Wanberg et al., (2003) & & $\mathrm{x}$ & $x$ & $\mathrm{x}$ & $\mathrm{x}$ & $\mathrm{x}$ & & $\mathrm{x}$ & $\mathrm{x}$ & \\
\hline Baugh \& Fagenson-Eland (2007) & & $x$ & & $x$ & $x$ & $x$ & $x$ & $x$ & $x$ & $x$ \\
\hline Dawson (2014) & & & $x$ & $x$ & $x$ & & $x$ & $x$ & & $x$ \\
\hline Integrated framework & $\mathrm{x}$ & $\mathrm{x}$ & $x$ & $\mathrm{x}$ & $\mathrm{x}$ & $x$ & $x$ & $\mathrm{x}$ & $\mathrm{x}$ & $\mathrm{x}$ \\
\hline
\end{tabular}

Source: Own elaboration developed from the mentoring literature. 


\subsubsection{Mentoring definition}

Only two of the frameworks studied provided a definition of mentoring (Anderson \& Shannon, 1988; Johnson, 2003). However, one of the key challenges about mentoring research is the lack of a generally accepted definition of mentoring (Jacobi, 1991; Crisp \& Cruz, 2009).

Whereas Jacobi (1991) identified 15 definitions of mentoring, Crisp \& Cruz (2009) counted up to 50 different definitions. Without delving into these definitions, some insights about them can be gained by delineating the actors ("who"), the content ("what") and the purpose ("why") identified in such definitions. A definition that takes into account the above analysis while drawing from the experience of mentoring practice in a university context will be proposed later. However, the quest for a definition is ongoing.

\subsubsection{Type of mentoring}

The mentoring relationship can either be formal or informal. Essentially, formal mentoring results from the efforts of decision makers and informal mentoring results from personal bonds between the mentor and the mentee reflecting common interests, goals, accomplishments, etc. Kram's (1985) pioneering work was based on informal mentoring. However, many organisations have created more formal and structured mentoring programmes in attempts to derive the benefits seen in informal mentoring (Ragins \& Cotton, 1999).

\subsubsection{Context of mentoring}

The context refers to the general environment within which the mentoring relationship takes place. Specifically, it includes the organisational culture, structure and processes. Such aspects as top management support for mentoring, the nature of interpersonal relationships or social networks in the organisation, reward and promotional system, affirmative action programmes, the hierarchical structure (multiple layers or flat), existence of opportunities for mentoring, level of job security, possibilities for career advancement, learning and development, etc., are all parts of the context (Hunt \& Michael, 1983; Gaskill, 1993; Wanberg et al., 2003).

\subsubsection{Programme structure}

The structure of the mentoring programme (especially for formal mentoring) refers to the guidelines and policies set by the management/administrators for its implementation. The nature of participation, whether voluntary or mandatory, frequency \& length of meetings, length of the mentoring relationship, the goals, aims or intentions of the relationship, content of mentoring dialogue, issues such as privacy or the use of technology, mentoring relationship monitoring, resolution of relationship conflicts, etc., are some of the main aspects which constitute the programme structures (Wanberg et al., 2003; Baugh \& Fagenson-Eland, 2007).

\subsubsection{Mentor characteristics}

The mentor's characteristics include both demographic and dispositional aspects. Such demographic characteristics include age, gender, race, ethnicity, socioeconomic background and education. The dispositional characteristics include such intangibles as locus of control, self esteem, affectivity, need for power, need for achievement, altruism, self confidence, learning goal orientation, work variables (interpersonal skills, work involvement/experience, work-family balance). Others are the mentor's character virtues, abilities or aptitudes and competencies. (Hunt \& Michael, 1983; Hegstad, 1999; Young \& Perrewé, 2000; Wanberg et al., 2003; Baugh \& Fagenson-Eland, 2007; Johnson, 2003).

\subsubsection{Mentee characteristics}

As with the mentor, the mentee characteristics include both demographic and dispositional aspects. Such demographic characteristics include age, gender, race, ethnicity, socioeconomic background, marital status and education. The dispositional characteristics include such intangibles as personality, locus of control, need for affiliation, need for autonomy, need for achievement, need for power, self esteem, learning goal orientation attitudes, high self monitoring, high emotional stability, communication competence, affectivity.

In addition to the above are other personal characteristics (interests and values), work variables (interpersonal skills, work involvement, job/career history, organisational rank, work experience, work-family balance), 
previous mentoring experience, career stage (Hunt \& Michael, 1983; Hegstad, 1999; Young \& Perrewé, 2000; Wanberg et al., 2003; Baugh \& Fagenson-Eland, 2007; Johnson, 2003).

\subsubsection{Matching process}

The matching process entails assigning a mentee to a mentor based on commonalities, similarity or complementarities - similar interests, career paths, alma maters, geographical locations, data from application forms, interviews and criteria-academic and interpersonal, recommendation, demographics, etc. Matching may also be through mentee's choice, mentor's choice, randomness, algorithms, or coordinator's judgment. Proper matching is crucial to the success of the relationship (Gaskill, 1993; Baugh \& Fagenson-Eland, 2007; Dawson, 2014).

\subsubsection{Mentoring relationship characteristics}

Within the mentoring relationship characteristics are the mentoring functions, mentoring phases and mentoring activities.

\subsubsection{Mentoring functions}

These functions refer to the different roles and behaviours exhibited by the mentors with respect to the mentees in the course of the relationship. In her pioneering study, Kram (1985) identified the mentoring functions as made up of career functions and psychosocial functions. The career functions refer to those aspects of the relationship that enhance the career development of the mentee by assisting him or her to learn the ropes of organisational life and to prepare for career growth. The career functions include sponsorship, assigning challenging tasks or assignments; coaching, protection, and providing exposure and visibility. The psychosocial functions, on the other hand, refer to those aspects of the relationship that enhance the mentee's sense of self worth and personal effectiveness. These include counselling, friendship, acceptance and confirmation and role modelling. Most studies have subsequently identified with Kram's career and psychosocial functions. However, Jacobi (1991) grouped the fifteen functions identified in her review into three components: emotional and psychological support, direct assistance with career and professional development, and role modelling. Crisp \& Cruz (2009) validated four major domains or functions comprising the mentoring relationship including psychological and emotional support, support for setting goals and choosing a career path, academic subject knowledge, and specification of a role model. These last two studies apply specifically to higher education contexts.

\subsubsection{Mentoring phases}

Mentoring phases refers to the different stages through which the mentor-mentee relationship develops through time. Hunt \& Michael (1983) identified four stages in the mentor-mentee relationship: the initiation stage, the mentee stage, break-up stage, and the lasting friendship stage. Kram (1983) also identified the phases of a mentoring relationship to be made up of initiation phase, cultivation phase, separation phase and redefinition phase. Most researchers who study mentoring phases (including in higher education contexts) adopt Kram's (1983) model (Mullen, 2007).

\subsubsection{Mentoring activities}

These are actions that mentors and mentees can perform during or within their relationship. Anderson \& Shannon (1988) gave some examples of basic mentoring activities in the area of teacher education to include: demonstrating teaching techniques to a mentee, observing mentee's classroom teaching and providing feedback, and holding support meetings with the mentee. Blackwell (1989) suggests that identified promising minority students may be invited to work with a professor on a major research project, or other creative enterprise - as a special assistant for library research for instance. In Aagaard \& Hauer (2003, p. 298) mentoring activity consisted of “[...] 10 to 15 students meeting with 2 faculty members for quarterly group dinners [...]”. Crisp \& Cruz's (2009) review identified various mentoring activities that have been proposed by different authors. These activities included access to mentoring videos, weekly college adjustment tips and participation in quarterly discussion groups, participation in undergraduate research or working with a mentor on research. Other activities identified were having two or more meetings and telephone conversations with a faculty member, letters from the programme office, an internet or video component as part of the students' mentoring activities, attending professional 
meetings, and participating in off-campus experiences. Nevertheless, one of the research gaps identified by Crisp \& Cruz, (2009) was the need to better understand the specific programmatic activities and characteristics that should be included in a theoretically-based, comprehensive mentoring experience. It is a given that there is little agreement regarding the specific activities that should be included.

In addition, some antecedents to mentoring relationships include the willingness of mentors and mentees to engage in the relationship, i.e., the mentee has to be willing to receive guidance and support and the mentor willing to give advice. This may depend on career goals and needs, career development, and career progression, general feeling towards mentoring, ability to thrive in relationships, position level, job experience and past experiences (Johnson, 2003). Other relevant antecedent variables (from interpersonal relationship theory) include the degree of attraction, similarity in attitude, and perceived commitment, general affect for mentoring, and power or performance potential of a partner. Other specific antecedents include intimacy, interpersonal perception, complementariness, mutuality, growth and learning (Anderson \& Shannon, 1988; Young \& Perrewé, 2000; Wanberg et al., 2003; Baugh \& Fagenson-Eland, 2007).

\subsubsection{Mentoring outcomes}

The outcomes refer to the results or consequences of the relationship. Such outcomes, both positive and negative, may refer to the mentee, mentor or the organisation. The more frequently cited mentee outcomes in workplace contexts are increased pay, greater personal and career satisfaction, career progress, faster promotions, greater professional confidence, greater career mobility, reduced work-family conflict, sense of enhanced power, increased self esteem, better company knowledge (Roch, 1979; Chao et al., 1992; Chao, 1997; Hunt \& Michael, 1983; Ragins \& Kram, 2007). In academic or higher education mentoring literature, the mentees' outcomes frequently encountered are higher retention, academic success/higher grades, social integration, satisfaction with college and adjustment to college (Crisp \& Cruz, 2009; Jacobi, 1991; Campbell \& Campbell, 1997; Ehrich et al., 2004). Other mentee outcomes identified include professional skill development, networking, initial employment, career eminence, personal health (Johnson, 2007), cognitive learning, skill-based learning, affective related learning, social networks, career commitment, organisational commitment, and lower turnover intention (Wanberg et al., 2003).

For the mentor, some of the frequently cited outcomes in workplace mentoring literature are learning, enhanced managerial skills, self reflection, confirmation, improved job performance, career success, rejuvenated career, increased confidence, respect and recognition by others, and a sense of personal fulfilment, commitment and satisfaction (Eby \& Lockwood, 2005; Ragins \& Kram, 2007; Hunt \& Michael, 1983; Kram, 1985; Johnson, 2007). Other mentor outcomes identified include collegiality and networking, positive reinforcement or constructive criticism, creative and rejuvenating life challenge, greater insight into mentees challenges, gaining information and prestige, enhanced professional and psychosocial development, increased visibility and organisational power, greater professional identity, loyal support from previous mentees, assistance with work from mentee, increased productivity, etc. (Ehrich et al., 2004; Ortiz-Walters \& Gilson, 2005). Negative outcomes include frustration, envy of mentee's progress, feelings of inadequacy, distancing behaviour, lack of needed expertise, lack of time and emotional energy, mentee disloyalty, loss of status, etc.

For the organisation in a workplace context, some of the frequently cited outcomes include better educated employees, more satisfied employees, early identification and development of managerial talent, reduced employee turnover, reduced frustrations, acclimatisation to company culture, enhanced networks through increased communication, increased productivity, improved employee motivation, performance and commitment, leadership development, promotion of organisational culture and philosophy, development of human resource function, competent workforce, bottom line effect, greater information exchange and socialisation, higher levels of perceived organisational justice, higher levels of organisational commitment, greater employee satisfaction, perpetuation of mentoring, smoother managerial succession, enhanced institutional memory, enhanced socialisation of new employees for better understanding of mission, values, and structure, enhanced performance leading to improved learning, career planning and development, enhanced diversity within management-women and minorities, etc. Negative outcomes include unsupportive organisational culture, lack of participant fit, relationship termination difficulties, etc. Other difficulties of mentoring for the organisation include lack of support, programme coordination difficulties, mentoring programme costs and resources. (Hunt \& Michael, 1983; Gaskill, 1993; Hegstad, 1999; Young \& Perrewé, 2000; Wanberg et al., 2003; Baugh \& Fagenson-Eland, 2007; Ehrich et al., 2004). Other general concerns (negative outcomes) related to mentoring identified in the literature include a lack of time for mentoring, poor planning of the mentoring process, unsuccessful matching of mentors and mentees, a lack of understanding about the mentoring process, and a lack of access to mentors from minority groups (Eby \& Lockwood, 2005). 


\title{
3.1.10. Programme support
}

These include orienting prospective mentees and mentors to the programme, broadening understanding of roles of mentors \& mentees, tackling such issues as the purpose of the programme, the mentoring functions, benefits and limitations of the programme and conflict handling, among a host of other items. The organisations can also provide training to address practical issues about relationships at different organisational levels, and about developing listening skills and problem solving techniques. Support also includes developing the content and process of training, encouraging information sharing among stakeholders, helping mentors to develop a necessary understanding and the skills for mentoring. Such support also specifies the mode, objectives, duration and regularity of mentor and mentee training. Technological or other artefacts are made available to assist mentors and mentees such as software and psychometric instruments, meeting room, stationery, reference manual, workbooks, pre-recorded video vignettes, etc.

For the evaluation of the programme, the main practices used include Formal/Informal assessment using questionnaires, and oral discussion about impressions, effectiveness and personal benefits, dyad involvement, performance and suggestions for improvement. Evaluation is also done through career progression, turnover, and placement rates (Baugh \& Fagenson-Eland, 2007; Gaskill, 1993; Dawson, 2014).

\section{Application of the integrated mentoring conceptual framework to the descriptive study of a mentoring programme for future engineers at a Spanish university}

Having explained the integrated mentoring conceptual framework with the key elements/components identified, we now apply it to the study of a more than 50-year old mentoring programme for future engineers at a Spanish university. This enables us to verify the usefulness of the framework in describing specific mentoring experiences. Moreover, the analysis of the mentoring experience with the framework allows us to identify areas for improvement.

\subsection{Mentoring definition}

Below we provide some responses of the faculty-mentors and student-mentees interviewed on: What is mentoring?

\begin{abstract}
Mentoring is guiding a student who comes to the university with lots of potential, aptitude, and who in given moments, needs to be guided on some specific matters or for all aspects of life such as putting together all resources to focus on the exams and personal development.
\end{abstract}

Mentoring is to have help when you need it. It can be of different types: aspects of study, practicums, including personal problems. Besides, it is to speak with someone who has experience and may have had to overcome the same challenges as yours.

Mentoring is a good way of receiving help and advice from persons who have experience and know more than you and can recommend to you the most appropriate advice for a given situation. It refers to academic, personal and professional ambits.

From the above descriptions and responses, we can define the mentoring practice at the engineering university as:

A formal process in which the students' affairs unit match each student-mentee with a faculty-mentor, based on perceived similarities between them such as gender, place of birth, language spoken and course of study and provides support that fosters trust between mentee and mentor, while the mentor helps the mentee to successfully transit into university life and to develop his or her academic, personal and professional qualities, through providing such functions as subject knowledge, befriending, supporting, counselling, role modelling and guiding.

\subsection{Type of mentoring}

The type of mentoring practised at the engineering university is formal in nature as the initiative was from the top management from its inception. The students are assigned to mentors by the students' affairs unit starting from their first year. The goals of the mentoring programme and some guidelines are set by the authorities. In addition, a third party (students' affairs unit) coordinates the mentoring process. 


\subsection{Context of mentoring}

The engineering university started more than fifty years ago and is located in the northern region of Spain. According to its mission, it sought to maintain a balance between teaching, research and having a real impact on society. It has an independent research centre attached to it. With respect to the students, it seeks to contribute to the professional, scientific and human development of future engineers. For that reason, the mentoring programme started at the same time as the start-up of the engineering university. Currently, there are a total of about 150 mentors in the institution. The proportion of female mentors is relatively high, hence a prevalence of same gender mentoring relationships. As mentioned above, the students' affairs unit is responsible for the coordination of the mentoring programme. The unit is made up of a head supported by an ad-hoc team of three faculty-mentors, a students' affairs coordinator and another staff member. Promotion of faculty is dependent more on an external regulating body following a number of parameters and mentoring is not one of these parameters.

\subsection{Programme structure}

The engineering university seeks to contribute to the integral development of the future engineers (the mentees) through the mentoring practice. The mentoring process is voluntary for the mentees. However, it is made available to all of them through a pairing process coordinated by the students' affairs unit. Moreover, the mentors explain the usefulness of the mentoring relationship to the mentees so that they perceive its importance and decide freely to participate. The mentors help the mentees with their experience and advice.

The goals of mentoring at the engineering university are four-fold: Firstly, it helps to inform and give orientation to the mentees at the beginning of their university studies. Secondly, it aids them in the development of good personal qualities and professional habits. Thirdly, it helps orient the mentees along the academic path, helping them in the selection of complementary courses and other social, sporting, cultural activities according to their capabilities and interests. Fourthly, it helps them make decisions with respect to their professional interests and according to their personal preferences, needs and qualities.

Furthermore, the role of group coordinators was created for ease of interaction and sharing of experiences amongst the mentors. A group coordinator is an experienced and committed faculty-mentor who "supervises" a group of about 12 other mentors. The students' affairs unit matches the mentors and the mentees, fixes the expected frequency of mentoring meetings or contacts between them, and regularly analyses the records of such contact frequency. The mentor/mentee relationship is expected to last the 4 or 5 years the mentees spend at the engineering university. The mentoring meeting between mentor and mentee is one-on-one, and face-to-face. The frequency of meetings varies for the first year mentees and the senior mentees. For the first year mentees, the suggested frequency of meetings is once every two weeks, while for the senior mentees the suggested frequency of meetings is at least nine times in an academic session.

However, in practice there are wide variations in the frequency of meetings between the mentoring dyads. The duration of each meeting depends on the level of communication established between them, the frequency of the meetings and the content of the conversations. It is estimated at between 15-20 minutes for each meaningful mentoring meeting. For reasons of order and good use of time, the mentor usually informs the students about the time and place where he/she will be available for the mentoring meetings. The mentor usually initiates the first few mentoring meetings using email or other means for arranging the appointments. The date and time for the subsequent meetings are usually agreed at the end of each mentoring meeting. Often, the mentoring meetings take place in the mentor's office or any other place within the university campus that ensures confidentiality, while avoiding interruptions. The content of mentoring conversations for the first year students usually revolves around adjustment issues and methods of study. For the more senior students, there is no specified content. The frequency of mentoring contacts is usually monitored with the aid of a mentoring information system.

\subsection{Mentor characteristics}

There are both male and female mentors. Although the majority of the mentors are faculty members, some administrative level staff are mentors as well. In this article they are all referred to as faculty-mentors. There are a total of about 150 of them at this institution. The majority of mentors are Spaniards (with a good percentage from the Basque region). 


\subsection{Mentee characteristics}

The mentees are both male and female future engineers with an age range between 17 and 22 years. Currently there are about 1000 student-mentees in the engineering university (2014-2015 academic session). Female mentees represent about 30\% of the mentee population. The mentees come from all parts of Spain. In addition, there are some foreign mentees, especially from Spanish speaking Central and South American countries. All the mentees are assigned mentors on their arrival at the institution, including those on short international exchange programmes.

\subsection{Matching process}

Initially, given the ratio of female mentors to female mentees, there were a few cross-gender relationships for the female mentees, but more recently with the presence of more female mentors, there are practically no cross-gender relationships. Some of the applicable criteria for mentor-mentee match are gender, high school attended, age of mentee, geographical origin and course of study (this is not always achievable given the limited variability in mentor characteristics). The matching is done by the students' affairs unit (coordinator's judgment), after obtaining opinion and input from the mentors regarding preferences (mentor choice). However, as the desire of the mentee is always respected, they are informed from the start about the possibility of changing their mentors, should there be need (mentee choice). All changes are done through the students' affairs unit.

\subsection{Mentoring relationship characteristics}

The mentoring relationship characteristics include mentoring functions, mentoring phases and mentoring activities.

\subsubsection{Mentoring functions}

The basic motivation of the mentor at the engineering university appears to be intrinsic (altruism). They seek to help in the integral formation or education of the student-mentees; specifically to help them to discover the importance of their university studies and their future career direction, to resolve the difficulties that arise; and to improve their academic performance. The more common mentoring functions exhibited by the mentors and sought by the mentees are those of befriending (gaining trust), supporting, role modelling (giving example), counselling (listening, advising), support for setting goals and choosing a career path, academic subject knowledge, guiding and developing. Following Kram's (1985) model, there are both psychosocial and career functions in the mentee-mentor relationship in this context.

\subsubsection{Mentoring phases}

The student-mentee is usually paired with the faculty-mentor from the first year. This marks the initiation phase. However the subsequent phases are not clearly demarcated into cultivation, separation and redefinition as described by Kram (1983). The relationship is planned to last the duration of each mentee's university career which is currently four years for undergraduate studies (almost six years for those who enrol in the Master's programme). In practice, there is high participation of the first year mentees in the mentoring programme being the period of transition from high school to the university. It could be said that the initiation phase is well demarcated. Nevertheless, once they overcome the academic challenges of the first year and obtain satisfactory grades there is a tendency for some of them to abandon the mentoring programme going directly to the separation phase. There seems to be no cultivation phase in many of the mentoring relationships. Although some of the mentees in their final year sometimes return to their mentors to seek advice on their professional career, elective courses, industrial placements and the Erasmus programme, the early separation from their mentors constrains the engineering university from achieving all the goals of the mentoring programme.

\subsubsection{Mentoring activities}

The mentoring activities in the first year of the relationship are relatively clear: learning new study techniques, learning the academic regulations and course requirements, resolving subject knowledge deficiencies, getting to know the campus and the city (especially those from other parts of the country and foreigners), etc. Given the 
totally new but relevant experiences involved, the mentees at this stage are often highly motivated to sustain the relationship with their mentors. However, one of the clear challenges for subsequent years or stages is the lack of such relevant activities that address the needs of the mentees at such stages.

With reference to the antecedents of mentoring at the engineering university, the student-mentees are mostly willing to receive guidance and support in their first year and the mentors are available to give advice especially on adjustment to university life and studies. At this stage, the student-mentees are completely inexperienced while they see their faculty-mentors as adults with experience about the university context covering such issues as subject matters, academic regulations, techniques for study, etc. The other antecedent variables such as degree of attraction, similitude, and general affect for mentoring, etc., become relevant in the relationship as from the second year, when the student-mentee has acquired some experience about university life and studies. Therefore, part of the challenge for the faculty-mentors is to work on these antecedents as well in the first year so as to sustain the relationship afterwards. The faculty-mentor can gain the trust of the students through role modelling acquired through well-prepared lectures/classes, order and punctuality, and constant readiness to attend to the needs of the mentees. The coherence in the faculty-mentor's life and the open and trusting relationship between him/her and the student-mentee are factors that help sustain the relationship.

\subsection{Mentoring outcomes}

After more than 50 years of mentoring experience at the engineering university, there have been multiple results and benefits. For the faculty-mentors, success in mentoring is measured by the level of trust and friendship established between them and their student-mentees and the satisfaction and personal fulfilment derived there-from. For the mentee, success meant he/she was satisfied with the relationship and has been able to graduate and to get a decent job afterwards. Specifically, the mentee outcomes include faster adjustment to university life, increased retention in the university, improved academic performance, acquisition of greater self knowledge and self leadership capabilities, access to a wide variety of cultural, sporting, social activities, and smooth transition to the labour market. Other benefits include engaging in research projects within the engineering university and participating in student international exchange programmes. Regarding the overall outcome from the perspective of the engineering university, two major benefits can be highlighted. On the one hand, there is the establishment of close relationships between faculty-mentors and student-mentees, which in the vast majority of cases goes beyond academics. This produces a harmonious working environment at the institution. From the top management there is a clear conviction that these relationships play a major role in the high level of satisfaction of the students, the pride of being students of this institution, the high number of committed alumni association members, and the number of students who are children of alumni (graduates), etc. The second benefit the mentoring programme brings to the engineering university is that it serves as a reminder to the faculty about the importance of students' overall development. This aspect may seem obvious, but it is easily blurred because faculty evaluation systems place more emphasis on teaching and research activities and the number of articles published in high impact journals. With an over-emphasis on research it is easily forgotten that the task of the faculty would be meaningless without the students and that a principal part of their task is ensuring mentee learning. The mentoring programme, as a fundamental aspect of the mission of the engineering university, makes faculty-mentors think constantly of how to improve the academic, personal and professional development of the mentees.

\subsection{Programme support}

Support for the mentoring programme and its evaluation at the engineering university are provided through the students' affairs unit. The types of support provided include an orientation session with the first year mentee's parents about the mentoring programme, initial formation for the new mentors, regular training of the mentors on different aspects of mentoring, providing mentoring activities, sharing relevant information with mentors and managing the mentoring information system (to capture and analyze mentoring data).

In addition, the students' affairs unit monitors the number and frequency of mentoring meetings between mentors and mentees from the mentoring information system. That data obtained gives an evaluation of the programme which aids decisions towards programme improvement. Evaluation of the mentoring programme is also carried out by a two-yearly survey of students, part of the requirements of the university regulating authority. Evaluation is also done through regular feedback meetings with the mentors' group coordinators. A yearly consolidated report of the mentoring programme is normally prepared for top management. 


\section{Discussion}

The description of the mentoring programme applying the key features identified from the integrated framework clearly shows the usefulness of the framework. Consequently, this has enabled us to understand better one of the oldest mentoring experiences in a non-English, Spanish speaking culture. Furthermore, the use of the framework in the concrete case allows us to identify aspects for improving the effectiveness of the programme.

From the elements above, we can describe the mentoring practice at the engineering university as formal, provided to all the mentees who desire it with the aim of helping them develop academically, professionally and humanly. The programme is coordinated by the student-affairs unit which assigns each student-mentee to a mentor, designs the training programmes for the mentors, defines the guidelines for mentoring conversations, identifies supporting activities and finally gathers information about the number and frequency of mentoring conversations over a given period. The programme is well developed for helping the mentees' transition to the university and to improve their study techniques.

Some mentees actually leave the mentoring programme when they have adapted to the university and when their academic performance starts to improve. This is because they do not perceive the usefulness of the programme henceforth. However, other mentees continue with the programme, increasing the level of trust with their mentors who listen, guide and serve as role models to them.

Among the benefits of this programme are reduction of the dropout rate, improvements in academic performance and the development of personal skills. However, the most prominent benefit is the interpersonal relationship generated and the level of satisfaction achieved by both mentees and mentors. This last point reflects the need for faculty to devote time to mentoring as one of their principal tasks, although it is not a main consideration for their promotion. Once the programme has been described we can see that the elements of the framework are present in the mentoring practice at the engineering university.

However, four specific aspects could be improved in the mentoring experience. First, the mentor and mentee's dispositional characteristics are not present in the mentoring programme at the engineering university. Such characteristics are currently not part of the employment and admission requirements. In the future, instruments may be developed to measure these dispositional characteristics and administered as part of the faculty/staff and student employment and admission processes, respectively. Secondly, the matching process from the framework could be more rigorous, with more criteria, than in the present programme. Given the importance of matching to formal mentoring programme success, wider and more relevant criteria for matching could be developed. Thirdly, although the goals and other guidelines of the mentoring programme are documented, it appears likely that the mentors and mentees are not fully aware of them. Moreover, whereas there are written documents and guides related to academic advising (study techniques and best practices), mentoring for personal and professional development of the student-mentee is left almost entirely to each mentor's experience, with no stated approaches for their development.

Fourthly, with regards to some antecedents of mentoring relationship, senior mentees' lack of willingness to engage in the relationship was the key challenge in the mentoring programme at the engineering university. This is reflected in the decline in number of mentoring meetings between faculty-mentors and students-mentees once the students get to their second year of study and beyond. The main reason for this is related to the lack of concrete method or approach for the personal and professional development of the mentees within the mentoring programme, after their first year. The programme lacks a skill-based learning approach for personal and professional development (Wanberg et al., 2003).

\section{Conclusions}

In this paper we have developed an updated integrated mentoring conceptual framework based on the study of previous frameworks and the mentoring literature. We have identified the key elements that include mentoring definition, type of mentoring, mentoring context, programme structure, mentor characteristics, mentee characteristics, matching process, mentoring relationship characteristics, mentoring outcomes, and programme support. This is a key contribution as we provide a more complete conceptualisation of mentoring.

Afterwards, we have applied the developed framework to the descriptive study of the more than 50 years mentoring practice at the engineering university in order to test and verify its usefulness for describing a mentoring practice for engineering students, and for identifying potential areas for its improvement. The fact that mentoring in this institution began about 20 years before the first mentoring publication by Kram (1983) makes it one of the oldest formal mentoring programmes for future engineers in the Spanish speaking, European world. Hence, we contribute by extending the mentoring literature with a concrete case of undergraduate 
mentoring in a non-English speaking context. In addition, the mentoring programme at the institution has been developed over the years without inputs from the results and conclusions of research. With this study, the elements of the integrated framework can now form the basis for the future growth and evolution of the mentoring practice and for the training of current and future mentors.

However, despite the above benefits, we have identified problems and areas for improvement in order to increase the effectiveness of the programme. The biggest challenge is caused by the apparent lack of willingness of some senior mentees to participate in the mentoring programme evidenced by the decreased number of mentoring meetings when their academic grades begin to improve. The mentoring approach that supports the personal development of the mentees, could be the missing ingredient needed to help them appreciate the usefulness of the mentoring meetings and hence maintain interest in their senior years.

What is the relevance of this developed framework to the engineering education community and research in general?

Firstly, the developed mentoring framework provides the elements that could be considered when designing and implementing a mentoring programme in general and specifically in faculties and schools of engineering, both at the undergraduate and postgraduate levels. Mentoring can help fresh engineering students transition from high school and to adapt to their new environment that is much tougher and many are not prepared for the rude shock! Mentoring extends engineering education beyond classroom and laboratory settings. Mentoring relationships can also involve senior faculty as mentors to junior faculty as mentees. It can also involve senior practicing engineers and the junior (pupil) engineers for the survival and growth of the engineering profession. Mentoring is an avenue to model the profession for the upcoming future engineers. With the outcome in mind, mentoring can help the engineering students develop essential non-technical skills such as communication, teamwork, time management skills, etc., through transfer of knowledge and experience by their faculty-mentors. This helps prepare them better for their future careers as engineers.

It is generally held that some of the challenges faced by engineering students are related to academic matters, faculty members and their project works. Others include psychological challenges (anxiety, depression and frustration), and difficulties inherent in the study of engineering and in accomplishing assigned tasks and the lack of problem solving skills, etc. Specifically, there exists the perception that faculty members don't care about their students given communication barriers between them (Nabila, 2014).

Mentoring relationships between faculty and engineering students, based on an understanding and implementation of the above framework can help address the aforementioned engineering education challenges. Such relationships also create a learning environment that is motivating and encouraging for the students, leading to improved academic performance. The image of engineering faculty members often seen as distant and only interested in technical things rather than persons can be improved by engaging in a mentoring relationship with the engineering students.

As in all research, this study has some limitations. First, the identification of the framework elements could have been done in a quantitative manner rather than qualitatively. Secondly, other elements from the mentoring experience could have been identified and incorporated into the integrated framework for its enrichment. Thirdly, the framework has been applied to the study of a single institution.

After the aforementioned limitations, some areas for future research have been identified. First, the framework could be applied to the descriptive study of other mentoring practices in other culturally different engineering education settings and the results compared. Secondly, a proposal for the design of specific schemes for the development of student-mentees' personal qualities and professional capabilities within the mentoring relationship is highly desirable. Thirdly, a study to develop instruments for measuring some of the dispositional characteristics of the mentors and mentees could aid proper matching of mentoring dyads. The framework can be used as a guide for designing future training programmes for current and prospective mentors.

\section{References}

Aagaard, E. M., \& Hauer, K. E. (2003). A cross-sectional descriptive study of mentoring relationships formed by medical students. Journal of General Internal Medicine, 18(4), 298-302. PMid:12709098. http://dx.doi.org/10.1046/j.1525-1497.2003.20334.x.

Allen, T. D., Eby, L. T., O’Brien, K. E., \& Lentz, E. (2008). The state of mentoring research: a qualitative review of current research methods and future research implications. Journal of Vocational Behavior, 73(3), 343-357. http://dx.doi.org/10.1016/j.jvb.2007.08.004.

Anderson, E. M., \& Shannon, A. L. (1988). Toward a conceptualization of mentoring. Journal of Teacher Education, 39(1), 38-42. http://dx.doi.org/10.1177/002248718803900109.

Baugh, S. G., \& Fagenson-Eland, E. A. (2007). Formal mentoring programs: a "poor cousin" to informal relationships? In B. R. Ragins \& K. E. Kram (Eds.), The handbook of mentoring at work: theory, research, and practice (250 p.). Thousand Oaks: Sage Publications. 
Bell, J. (2005). Doing your Research Project: a guide for first-time researchers in education, health and social science. (4th ed.) Berkshire: Open University Press.

Blackwell, J. E. (1989). Mentoring: an action strategy for increasing minority faculty. Academe, 75(5), 8-14. http://dx.doi.org/10.2307/40249734.

Campbell, T. A., \& Campbell, D. E. (1997). Faculty/student mentor program: effects on academic performance and retention. Research in Higher Education, 38(6), 727-742. http://dx.doi.org/10.1023/A:1024911904627.

Chao, G. T. (1997). Mentoring phases and outcomes. Journal of Vocational Behavior, 51(1), 15-28. http://dx.doi.org/10.1006/jvbe.1997.1591.

Chao, G. T., Walz, P., \& Gardner, P. D. (1992). Formal and informal mentorships: a comparison on mentoring functions and contrast with nonmentored counterparts. Personnel Psychology, 45(3), 619-636. http://dx.doi.org/10.1111/j.1744-6570.1992.tb00863.x.

Crisp, G., \& Cruz, 1. (2009). Mentoring college students: a critical review of the literature between 1990 and 2007. Research in Higher Education, 50(6), 525-545. http://dx.doi.org/10.1007/s11162-009-9130-2.

Dawson, P. (2014). Beyond a definition: toward a framework for designing and specifying mentoring models. Educational Researcher, 43(3), 137-145. http://dx.doi.org/10.3102/0013189X14528751.

Eby, L. T., \& Allen, T. D. (2008). Moving toward interdisciplinary dialogue in mentoring scholarship: an introduction to the Special lssue. Journal of Vocational Behavior, 72(2), 159-167. PMid:19343082. http://dx.doi.org/10.1016/j.jvb.2008.02.005.

Eby, L. T., \& Lockwood, A. (2005). Proteges' and mentors' reactions to participating in formal mentoring programs: a qualitative investigation. Journal of Vocational Behavior, 67(3), 441-458. http://dx.doi.org/10.1016/j.jvb.2004.08.002.

Eby, L. T., Rhodes, J. E., \& Allen, T. D. (2007). Definition and evolution of mentoring. In T. D. Allen \& L. T. Eby (Eds.), The blackwell handbook of mentoring. a multiple perspectives approach (1st ed., pp. 14-17). Oxford: Blackwell Publishing.

Ehrich, L. C., Hansford, B., \& Tennent, L. (2004). Formal mentoring programs in education and other professions: a review of the literature. Educational Administration Quarterly, 4O(4), 518-540. http://dx.doi.org/10.1177/0013161X04267118.

Fuentes, M. V., Alvarado, A. R., Berdan, J., \& DeAngelo, L. (2014). Mentorship matters: does early faculty contact lead to quality faculty interaction? Research in Higher Education, 55(3), 288-307. http://dx.doi.org/10.1007/s11162-013-9307-6.

Gaskill, L. R. (1993). A conceptual framework for the development, implementation, and evaluation of formal mentoring programs. Journal of Career Development, 20(2), 147-160. http://dx.doi.org/10.1177/089484539302000205.

Gershenfeld, S. (2014). A review of undergraduate mentoring programs. Review of Educational Research, 84(3), 365-391. http://dx.doi. org/10.3102/0034654313520512.

Gerstein, M. (1985). Mentoring: an age old practice in a knowledge-based society. Journal of Counseling and Development, 64(2), 156-157. http://dx.doi.org/10.1002/j.1556-6676.1985.tb01061.x.

Hegstad, C. D. (1999). Formal mentoring as a strategy for human resource development: a review of research. Human Resource Development Quarterly, 10(4), 383-390. http://dx.doi.org/10.1002/hrdq.3920100408.

Hunt, D. M., \& Michael, C. (1983). Mentorship: a career training and development tool. Academy of Management Review, 8, 475-485.

Jacobi, M. (1991). Mentoring and undergraduate academic success: a literature review. Review of Educational Research, 61(4), 505-532. http://dx.doi.org/10.3102/00346543061004505.

Johnson, W. B. (2003). A framework for conceptualizing competence to mentor. Ethics \& Behavior, 13(2), 127-151. http://dx.doi. org/10.1207/S15327019EB1302_02.

Johnson, W. B. (2007). Student-faculty mentorship outcomes. In T. D. Allen \& L. T. Eby (Eds.), The blackwell handbook of mentoring, a multiple perspectives approach (1st ed., 189 p.). Oxford: Blackwell Publishing.

Kezar, A. J., \& Kinzie, J. (2006). Examining the ways institutions create student engagement: the role of mission. Journal of College Student Development, 47(2), 149-172. http://dx.doi.org/10.1353/csd.2006.0018.

Kram, K. E. (1983). Phases of the mentor relationship. Academy of Management Journal, 26(4), 608-625. http://dx.doi.org/10.2307/255910.

Kram, K. E. (1985). Mentoring at work: developmental relationships in organizational life.

Miles, M. B., \& Huberman, A. M. (1994). Qualitative data analysis (2nd ed.). Thousand Oaks: Sage Publications.

Mullen, C. A. (2007). Naturally occurring student-faculty mentoring relationships: a literature review. In T. D. Allen \& L. T. Eby (Eds.), The blackwell handbook of mentoring, a multiple perspectives approach (1st ed., pp. 119-138). Oxford: Blackwell Publishing.

Nabila, Y. A. (2014). Engineering education and students' challenges: strategies toward enhancing the educational environment in engineering colleges. College Student Journal, 2, 221-230.

Ortiz-Walters, R., \& Gilson, L. L. (2005). Mentoring in academia: an examination of the experiences of mentees of color. Journal of Vocational Behavior, 67(3), 459-475. http://dx.doi.org/10.1016/j.jvb.2004.09.004.

Ragins, B. R., \& Cotton, J. L. (1999). Mentor functions and outcomes: a comparison of men and women in formal and informal mentoring relationships. The Journal of Applied Psychology, 84(4), 529-550. PMid:10504893. http://dx.doi.org/10.1037/0021-9010.84.4.529.

Ragins, B. R., \& Kram, K. E. (2007). The handbook of mentoring at work: theory, research, and practice. Thousand Oaks: Sage Publications.

Roch, G. R. (1979). Much ado about mentors. Harvard Business Review, 571), 14-20. PMid:10244210.

Wanberg, C. R., Welsh, E. T., \& Hezlett, S. A. (2003). Mentoring research: a review and dynamic process model. Research in Personnel and Human Resources Management, 22, 39-124.

Young, A. M., \& Perrewé, P. L. (2000). The exchange relationship between mentors and mentees: the development of a framework. Human Resource Management Review, 10(2), 177-209. http://dx.doi.org/10.1016/S1053-4822(99)00045-5.

Received: Sept. 8, 2016

Accepted: Apr. 27, 2017 